\title{
HIGHER EDUCATION IN THE ERA OF GLOBAL DIGITALIZATION: MAIN TRENDS AND DEVELOPMENT PROSPECTS
}

\author{
Ekaterina Kupchina \\ Associate professor, RUDN University, RUSSIA, belousova-ev@rudn.ru
}

\begin{abstract}
Digital technologies have long been an integral part of the daily life of a modern person. From a very early age, children begin to master all kinds of interactive games and devices that help in the development, and over time, move on to more complicated technical devices and software.

There is no doubt that modern global digitalization affects all educational process stages: from pre-school education to postgraduate and doctoral studies. However, higher educational institutions by far occupy the leading positions in using digital technologies in the educational process.

In 2020, the COVID-19 pandemic broke out in the world, which led to the transition of the entire education system to a distance format and, as a result, the rapid development of the electronic educational environment.
\end{abstract}

Many universities worldwide have long been working on creating e-learning courses and educational platforms based on existing software. However, such courses were considered only as an alternative to the main approaches to the educational process. Their primary purpose was to attract a broader mass of students to the educational process, simplify access to electronic libraries, and fulfill the tasks.

In self-isolation and adherence to social distance, the electronic educational environment has become the only possible way out of this situation. It has become a starting point on the way to more advanced approaches to implementing educational technologies.

In this work, the author analyzes modern digital technologies in higher education and identifies the main positive and negative aspects of their application.

The article aims at:

- Identifying and analyzing the main methods and means of implementing digital educational technologies in higher education institutions;

- Identifying the main trends associated with the digitalization of the higher education system as a whole;

- Developing recommendations for improving the e-learning system.

The research's methodological basis is formed by general scientific methods of cognition, including systemic, formal-logical, and structural-functional analysis. The research's scientific novelty lies in a comprehensive study of the problems arising in the higher education system and the use of an electronic learning format, identifying positive and negative aspects in implementing this approach to learning.

This research can be used to develop training courses, educational and methodological sets, and improve the higher education system. This article's conclusions and materials can be used in research, teaching, lectures, and seminars in the relevant disciplines.

Keywords: digitalization, higher education, distance learning, e-courses. 


\section{INTRODUCTION}

Digital technologies have long been firmly entrenched in all spheres of human life. Undoubtedly, the higher education system can be attributed to one of the areas of widespread use of digital technologies. The crucial factors that determine the processes of digitalization in a university are increasing competitive advantages in the educational services market, the availability of higher education to a wider range of society, a possible reduction in the cost of education by distance learning formats, the ability to vary the duration of training. The situation that the entire education system has faced in 2020, related to the spread of COVID-19, accelerated the transition to a digital learning environment. Analyzing the innovative processes of using digital technologies in higher education, it seems possible to assess the degree of readiness of higher educational institutions for the widespread use of this technology and future development prospects.

Digital transformation in the higher education system implies sustainable management mechanisms to quickly adapt to changes associated with the use of new technologies. Digital technologies in education create favorable conditions for the systematization and development of educational processes. By reducing the volume of classroom work, and the transition to the interaction between students and teachers in a digital format, students' development of independence and individual abilities is stimulated (Kupchina E., 2020). Besides, online learning allows teachers and course creators to update and improve coursework continually.

However, there is no talk of a complete transition to a digital format of education and the replacement of traditional approaches with online ones. Digital technologies are considered a useful tool for improving approaches to organizing education in the higher education system.

\section{METHODOLOGY}

The research's main methods are general scientific methods of cognition, including systemic, formal, and logical, structural, and functional analysis. The study of the problems arising in higher education, and the use of digital technologies in the educational environment, was carried out through specific research, logical, statistical, and content analysis. The analysis of the current practice, the systematization, and the generalization of the studied material allowed the author to conclude the urgent tasks for forming a sound approach to introducing digital technologies in education. In her work, the author relied on Russian and foreign theoretical scientists' opinions in the considered and related fields of knowledge.

\section{RESULTS}

\subsection{Digital transformation in the Education Sector}

\subsubsection{Prerequisites for the Creation of a Global Digital Educational Environment}

From year to year, the digital transformation of modern society is only gaining momentum. The rapid development of science and technology in the past decade could not but affect the processes taking place in higher education. The process of digital education formation can be conditionally divided into two groups:

- In terms of development and implementation of new technologies;

- From the point of view of social processes taking place in society.

In the field of social relationships when organizing communication, there has recently been a transition to the use of mobile devices, computers, communication in social networks on the Internet (Belousova A., 2017). Children actively use and interact with all kinds of gadgets from a very early age, which makes the above communication tools familiar. In this context, the use of digital technologies in modern students' educational process is becoming a natural and integral component (Mamychev A.Yu., 2020). From the point of view of the organization of the educational process, at the initial stage, the process of introducing new technologies affected, to a large extent, only teachers, for example, creating a teacher's portfolio in a digital environment which indicates the main scientific achievements (speeches at scientific conferences, a list of major publications, and others). Unfortunately, not all teachers were able to adapt to the new requirements quickly. For some teachers, the transition to digital reporting and student assessment has been painful. However, for many, this served as a starting point on the path to mastering new technologies and improving their digital literacy. Also, an important role in the formation of the digital education system was played by assessing students' knowledge according to the scoring system under the list of competencies, the formation of which the training course is aimed at. There is an opinion that with the further introduction of digital technologies into the educational environment, a computer program can be developed that allows, based on specific algorithms, to fix the answers and assess the knowledge of students. 
Concerning the introduction of modern technical means in the student learning process organization, it should be emphasized that the first step towards creating a digital learning environment was the use of the so-called "analog" means-for example, smart boards, use of projectors and multimedia equipment in classrooms, PowerPoint presentations. The process of step-by-step digitization of university literature was also started.

The introduction of these technologies made it possible to significantly increase the audience's interest in higher education, expanding the tools and methods available in the teacher's arsenal for organizing training, which has led to an increase in the quality of the educational services provided.

\subsubsection{Digital Transformation of Modern Higher Education}

The main driving factor for the promotion of the digital format of education in the educational services market is

- An increase in the flow of incoming and outgoing academic mobility;

- An increase in demand for high-quality educational services, and

- Advanced training on the part of those who have already had higher education,

- A possible reduction in the cost and duration of training.

Many universities have been working on creating their digital infrastructure over the past ten years. However, compared to the pace of global digitalization, this process can be called relatively "inert." At present, creating one's online educational platforms, filling with digital content, and the transition of individual courses into digital format cannot be called practical tools for forming a digital education system. A study conducted among Russian universities showed that by the beginning of $2020,13 \%$ of universities do not even have necessary digital infrastructure. There is no high-speed Internet access; existing servers' capacity is not enough to host information systems and store relevant data. Only $11 \%$ of higher education institutions have a digital infrastructure that fully meets all modern requirements and is sufficient for the full-fledged organization of online education (IAU, 2020).

Creating an effective system of modern higher education requires the development of unique ways of organizing and supporting the educational process (Dudin, M.N., 2019). Modern digital educational technologies provide ample opportunities to develop further established traditional forms of education and the transition to a qualitatively new level. Nevertheless, attempts to expand the range of digital tools in education are criticized continuously and face problems with a lack of funding and an appropriate technical base.

The priority that needs to be addressed at this time is the issue of investing in information and communication technologies. Creating a system of practical state support in technological infrastructure, teacher training, and maintenance will accelerate the digitalization of higher education. Currently, the high cost of digital technology is forcing universities to form alliances to co-finance and share costs and the use of resources and infrastructure.

The most acute problem at present is the problem of teaching faculty to work with digital tools online. Many "old school" representatives actively resist and refuse to accept the introduction of modern technologies into the educational process, which negatively affects the digitalization processes (Dudin, M.N., 2018).

An essential factor in forming a digital educational environment is the creation of educational sets and their translation into an online format. This is an essential element since the learning process's effectiveness directly depends on how much students can perceive the information contained in these sets.

It was evident that the digitalization of the higher education system contributes to the following factors:

- Improving the quality of fundamental education;

- Reaching a wider audience of students through the use of distance learning formats;

- Development of independence and creative potential of the personality among students.

There is no doubt that the process of introducing information technologies into the higher education system is an adequate response to the challenges of modern digital society (Gronik I., 2020). When Comparing the traditional format of education with the digital one, the question often arises of assessing the latter's effectiveness. Studies conducted in recent years show that it is still too early to necessary conclusions because the process of global digitalization in education is at its initial stage. 


\subsubsection{Impact of COVID-19 on the Digitalization of Higher Education}

The spread of coronavirus infection in early 2020 has become a powerful catalyst for the development of digital technologies in education. Almost all the available training courses were quickly transferred to the online format. Students and teachers, being in self-isolation, were deprived of personal communication within the university facilities. This required an immediate response from national governments and online education institutions (Dieu Hack-Polay, 2020). During the unprecedented measures taken, and taking into account the degree of readiness of universities for the transition to digital format, several modes of training can be distinguished:

- Asynchronous or correspondence;

- ᄀSynchronous;

- $\neg$ Blended

Students received assignments from teachers by e-mail or other means of communication in the asynchronous or part-time mode of study. However, from the perspective of the effectiveness and quality of teaching, this approach was accepted only by those universities whose material, technical and digital support did not allow resorting to other formats.

The synchronous training mode implies students' and teachers' simultaneous participation in conducting classes, for example, in a webinar format. This approach made it possible to minimize the loss of the taught disciplines' quality and maintain the level of student involvement in the educational process.

Blended learning uses a synchronous and asynchronous format of interaction between students and teachers. This mode turned out to be the most effective. However, not all universities were able to provide it, which indicates that some higher educational institutions are lagging modern requirements in the educational process's management and organization.

Considering the above, we can highlight the main problems faced by higher educational institutions in the organization of large-scale training in the online environment:

- Shortage or complete absence of individual tools and equipment (many students did not have personal computers or other devices that would allow them to continue their studies online;

- Absence or weak signal of the Internet for teachers and students;

- Lack of licenses and experience in using video conferencing facilities for an educational organization;

- Issues of information security to protect infrastructure and systems from external threats.

As a result of the work carried out and efforts on the part of the administration of universities, the following results were achieved:

- Implementation of information systems and services into the educational process (for example, Learning Management System);

- Additional licenses were purchased, the capacities of cloud services were increased;

- Methodological and technological assistance to teachers and staff was organized ("digital volunteering");

- $\neg$ Centralized access to services Zoom, MS Teams, and others was organized.

Probably, after the threat of the spread of coronavirus infection has passed, the lives of many people will return to their usual course. However, such large-scale changes will leave their mark on the entire higher education system. Discussions are already underway to develop a useful blended learning model that combines traditional learning approaches and a digital format.

\section{CONCLUSION}

The study showed that introducing information technology into the organization of training has more favorable characteristics. Digital technologies in education have made it possible not only to make the learning process more attractive but also to cope with the tasks set in the context of the COVID-19 epidemic without significantly reducing the quality of educational services. It should also be emphasized that in the conditions of a complete lockdown, based on the most progressive universities in terms of digitalization processes, online communities of students, teachers, and administration were created, which contributed to an increase in the quality of education and a decrease in the stress of social isolation. 
Besides, the widespread use of digital technologies in teaching made it possible to identify existing problems in universities' technical and methodological support. Using digital technologies in education has shown that there are some problems and tasks that can only be solved over time, but without digital technologies, the further development of the education system is no longer possible.

\section{ACKNOWLEDGMENTS}

This work has been financially supported by the Grant of the President of the Russian Federation №. HШ2668-2020.6 «National-Cultural and Digital Trends in the Socio-Economic, Political and Legal Development of the Russian Federation in the 21st Century».

\section{REFERENCE LIST}

Kupchina, E. (2020) The university course "Protection of Intellectual Rights" in the training of a corporate lawyer. 10th International Conference the Future of Education - Virtual Edition. Edited by Pixel. Florence, Italy, pp. 285-289

Belousova, A., Ilyashevich M., Kupchina Y., Belousov A. (2017) Students perceptions on teaching styles within public international law curriculum: a case of Russia. Eurasia Journal of Mathematics, Science and Technology Education.Vol. 13. № 10. pp. 6945-6952.

Mamychev, A.Yu., Kim, A.A., Frolova, E.E. (2020) "Future" as an attractor of modern political, legal and socio-economic transformations: an overview of the main problems and approaches. Advances in Law Studies. Vol. 8. No. S5. pp. 3-17.

IAU (2020) The Impact of COVID-19 on Higher Education around the World URL: https://iauaiu.net/Covid19-Higher-Education-challenges-and-responses (Date of access: 16.12.2020)

Dudin, M.N., Shakhov, O.F., Shakhova, M.S., Rusakova, E.P., Sizova, Y.S. (2019) Digital technologies as a driver of intellectual stratification of human resources: socio-economic inequality. International Journal of Recent Technology and Engineering. 2019. Vol. 8. No 2, 4436-4440.

Dudin, M.N., Bezbakh, V.V., Frolova, E.E., Galkina, M.V. (2018) The models of higher education in Russia and European countries at the beginning of the XXI century: the main directions of development. European Journal of Contemporary Education. 2018. Vol. 7, No 4. 653-667.

Irina Gronik (2020). Distance Learning: A New Perspective to the Future. 10th International Conference the Future of Education - Virtual Edition. Edited by Pixel. Florence, Italy, pp. 203-207.

Dieu Hack-Polay (2020) COVID-19 and HE COVID-19 and internationalization in Higher Education. Can an elusive virus redefine higher education internationalization strategy? URL: https://www.researchgate.net/publication/341448317 (Date of access: 20.12.2020) 